\title{
Dukungan Sosial dan Subjective Well Being Siswa Sekolah Singosari Delitua
}

\section{Social Support and Subjective Well Being Students Singosari Delitua School}

\author{
M. Fadli Nugraha \\ Fakultas Psikologi, Universitas Medan Area, Indonesia
}

Diterima : 17 Maret 2020; Disetujui : 11 April 2020; Dipublish : 30 April 2020

*corresponding author: de.fazly@yahoo.de

\begin{abstract}
Abstrak
Tujuan penelitian ini untuk melihat gambaran dukungan sosial dan subjective well being siswa yang ada di sekolah Singosari Kecamatan Delitua, Kabupaten Deli Serdang. Metode penelitian menggunakan kuantitatif deskriptif. Teknik pengambilan sampel menggunakan total sampling. Populasi seluruh siswa kelas 12 dan sampelnya sebanyak 100 siswa. Instrumen penelitian menggunakan skala jenis likert. Analisis data menggunakan analisis deskriptif. Hail penelitian menunjukkan bahwa secara keseluruhan dukungan sosial siswa rendah. Terlihat dari hasil empiris dari dukungan emosional hanya 2 siswa yang tinggi dan 30 siswa sedang dan 68 siswa rendah. Dukungan penghargaan tidak memiliki siswa yang tinggi dan sendang ada 24 siswa, rendah ada 76 siswa. Dukungan instrumental ada 6 siswa tinggi, 19 siswa sedang dan 75 rendah. Kemudian dukungan informatif ada 4 siswa tinggi, 31 sedang dan 65 rendah. Kemudian siswa yang indikator kebahagiaannya tinggi ada 3, sedang 26 dan rendah 71 siswa. Indikator kepuasan hidup ada 2, sedang 32 dan rendah 66 siswa.
\end{abstract}

Kata Kunci: Dukungan Sosial; Subjective Well Being.

\section{Abstract}

The purpose of this study is to see a picture of social support and subjective well-being of students in the Singosari school, Delitua District, Deli Serdang Regency. The research method uses quantitative descriptive. The sampling technique uses total sampling. The population is all 12th grade students and the sample is 100 students. The research instrument uses a Likert type scale. Data analysis uses descriptive analysis. Results of research that show social facts about students are low. Only 2 students were high and 30 students were moderate and 68 students were low. There are no students who have high students and there are 24 students, there are 76 students low. Instrumental support there are 6 high students, 19 medium students and 75 low. There are 4 students, 31 medium and 65 low. Then the students with high happiness indicators were 3, medium 26 and low 71 students. There are 2 indicators of life satisfaction, 32 being and 66 being low.
\end{abstract}

Keywords: Social Support, Subjective Well Being.

Rekomendasi mensitasi :

Nugraha, M.F. (2020), Dukungan Sosial dan Subjective Well Being Siswa Sekolah Singosari Delitua. Jurnal Penelitian Pendidikan, Psikologi dan Kesehatan (J-P3K). 1 (1): 1-7. 


\section{PENDAHULUAN}

Kebahagiaan siswa akan menjadi tolak ukur untuk melihat apakah seorang siswa nyaman berada di sebuah sekolah tersebut dengan harapan prestasi belajar siswa menjadi lebih baik. Kebahagiaan sudah lama menjadi objek penelitian untuk melihat dan mengukur sebuah keadaan, karena dengan puas nya individu dengan dirinya sendiri maka kebahagiaan itu dapat hadir dengan sendirinya.

Harapan masyarakat kepada generasi muda yang besar membuat sekolah harus berpacu meningkatkan mutu pendidikan yang tanpa disadari siswa cenderung mengalami tekanan sehingga menimbulkan stres karena dampak dari tugas di sekolah yang padat yang biasanya dilanjutkan dengan tugas di rumah ketat dan memiliki waktu yang singkat, hal ini akan berdampak pada subjective well being siswa.

Kebahagiaan itu menjadi penting dan menjadi tolak ukur kemajuan pendidikan di Indonesia dan kebahagiaan yang dirasakan dan dinilai oleh siswa itu sendiri disebut subjective well being. Seperti yang dikatakan oleh Diener, Oishi, \& Lucas (Darusmin, 2015) subjective well being adalah analisis ilmiah tentang bagaimana individu melakukan evaluasi terhadap kehidupannya, termasuk sejumlah kenangan yang telah lama berlalu.

Evaluasi-evaluasi ini melibatkan reaksi emosional individu terhadap sejumlah peristiwa kehidupan, suasana hati, serta penilaian mereka terhadap kepuasan hidup, kebermaknaan, dan kepuasan pada domain spesifik dari kehidupan. diperlukan dukungan sosial sebagai dorongan kebahagiaan siswa dari sisi luar dirinya. Dukungan sosial menjadi penting karena manusia secara umum memiliki kebutuhan sosial untuk memberi umpan balik atau ikatan emosional yang memberikan kepuasan dan bisa juga menjadi saling tukar informasi yang akan membuat manusia itu tidak hanya tumbuh fisiknya namun juga dapat berkembang kognitifnya. Pada akhirnya akan meningkatkan kebahagiaan manusia itu sendiri dalam hal ini akan meningkatkan subjective well being siswa itu sendiri.

Sejalan dengan hal tersebut menurut Johnson dan Jhonson (Saputri, 2011) bahwa dukungan sosial merupakan keberadaan orang lain yang dapat diandalkan untuk memberi bantuan, semangat, penerimaan dan perhatian, sehingga bisa meningkatkan kesejahteraan hidup bagi individu ang bersangkutan. Dukungan sosial yang diterima oleh orang yang berada diantara siswa akan sangat membantu siswa lebih bahagia.

Demikian juga menurut Roberts \& Gilbert (Kusrini, 2014) dukungan sosial dapat dianggap sebagai sesuatu keadaan yang bermanfaat bagi individu yang diperoleh dari orang lain yang dapat dipercaya. Pada keadaan tersebut individu akan mengetahui bahwa orang lain memperhatikan, menghargai, dan mencintai dirinya. Dukungan sosial adalah suatu pemikiran terbaik sebagai suatu konstruk multidimensional yang terdiri dari komponen fungsional dan struktural. Dukungan sosial merujuk kepada tindakan yang orang lain lakukan ketika mereka menyampaikan bantuan. 
Subjective well being akan tercapai bila dukungan sosial yang diterima cukup bagi siswa baik dari teman sebaya maupun dari pihak sekolah dan orang tua. Dukungan sosial berhubungan dengan subjective well being karena dianggap mempengaruhi subjective well being siswa karena ada dorongan semangat hidup dari luar diri siswa itu sendiri, seperti yang dinyatakan oleh Diener, Suh, Lucas \& Smith (Ariati, 2010) Terdapat enam hal yang dapat dijadikan sebagai prediktor terbaik dalam mengetahui kebahagiaan dan kepuasan dalam hidup yaitu salah satunya adalah relasi sosial yang positif, berteman dengan selalu melakukan halhal yang positif juga akan meningkatkan kebahagiaan pada setiap individu karena tidak adanya rasa negatif. jadi relasi sosial akan tercipta bila adanya dukungan sosial dan keintiman emosional.

\section{METODE PENELITIAN}

Metode dalam penelitian ini adalah kuantitatif deskriptif. Tujuan penelitian ini untuk melihat gambaran dukungan sosial dan subjective well being siswa. Metode penelitian menggunakan kuantitatif deskriptif. Teknik pengambilan sampel menggunakan total sampling. Populasi seluruh siswa kelas 12 dan sampelnya sebanyak 100 siswa. Instrumen penelitian menggunakan skala likert.

Subjective well being diukur dengan menggunakan teori dari Compton (Darusmin, 2015), melibatkan dua variabel utama, yaitu kebahagiaan (happiness) dan kepuasan hidup (satisfaction with life). Kebahagiaan akan terkait dengan bagaimana keadaan emosi individual dan bagaimana mereka merasakan kehidupannya. Kepuasan hidup akan mengarah pada penilaian yang lebih luas tentang penerimaan masingmasing orang terhadap kehidupannya. Dukungan sosial diukur berdasarkani transaksi interpersonal yang melibatkan satu atau lebih aspek-aspek yaitu, dukungan emosional, penghargaan, instrumental, informatif.

\section{HASIL DAN PEMBAHASAN}

Pengujian normalitas data untuk masing-masing data variabel menggunakan analisis kolmogorovsmirnov pada program SPSS. Hasil uji normalitas menunjukkan data kedua variable normal dengan $\mathrm{p}>0.050$ yang dapat dilihat pada tabel dibawah ini:

\begin{tabular}{llll}
\multicolumn{4}{l}{ Tabel 1. Uji Normalitas } \\
\hline Variabel & K-S & P & Ket. \\
\hline $\begin{array}{l}\text { Dukungan } \\
\text { Social }\end{array}$ & 0.086 & 0.064 & Normal \\
\hline $\begin{array}{l}\text { Subjective } \\
\text { Well Being }\end{array}$ & 0.083 & 0.086 & Normal \\
\hline
\end{tabular}

Berikut adalah hasil data dukungan sosial deskriptif yang dilakukan di sekolah tersebut.

Tabel 2. Hasil Deskriptif Dukungan Sosial

\begin{tabular}{llll}
\hline Indikator & Tinggi & Sedang & Rendah \\
\hline $\begin{array}{l}\text { Dukungan } \\
\text { Emosional }\end{array}$ & 2 & 30 & 68 \\
\hline $\begin{array}{l}\text { Dukungan } \\
\text { Penghargaan }\end{array}$ & - & 24 & 76 \\
\hline $\begin{array}{l}\text { Dukungan } \\
\text { Instrumental }\end{array}$ & 6 & 19 & 75 \\
\hline $\begin{array}{l}\text { Dukungan } \\
\text { Informatif }\end{array}$ & 4 & 31 & 65 \\
\hline
\end{tabular}

Berdasarkan hasil analisis deskriptif pada 100 siswa diketahui bahwa secara keseluruhan dukungan sosial siswa rendah. Terlihat dari hasil empiris dari dukungan emosional hanya 2 siswa yang tinggi dan 30 siswa sedang dan 68 siswa rendah. Dukungan penghargaan tidak 
memiliki siswa yang tinggi dan sendang ada 24 siswa, rendah ada 76 siswa. Dukungan instrumental ada 6 siswa tinggi, 19 siswa sedang dan 75 rendah. Kemudian dukungan informatif ada 4 siswa tinggi, 31 sedang dan 65 rendah.

Selanjutnya dalam tabel 3 berikut menggambarkan hasil penelitian menggunakan analisis statistik deskriptif subjective well being.

Tabel 3. Hasil Deskriptif Subjective Well Being

\begin{tabular}{llll}
\hline Indikator & Tinggi & Sedang & Rendah \\
\hline Kebahagiaan & 3 & 26 & 71 \\
\hline $\begin{array}{l}\text { Kepuasan } \\
\text { Hidup }\end{array}$ & 2 & 32 & 66 \\
\hline
\end{tabular}

Berdasarkan hasil analisis deskriptif pada 100 siswa diketahui bahwa siswa yang indikator kebahagiaannya tinggi ada 3 , sedang 26 dan rendah 71 siswa. Indikator kepuasan hidup ada 2, sedang 32 dan rendah 66 siswa.

Hasil dari analisis deskriptif diatas menunjukkan bahwa dukungan sosial yang diterima siswa sangat rendah yang dapat dilihat dari dominasi rendahnya dukungan sosial setiap indikator. Bahkan salah satu indikator tidak memiliki rasa dukungan yang tinggi.

Hal ini juga akan mempengaruhi suasana belajar mengajar dan bahkan prestasi belajar siswa. Hal ini dapat dilihat dari fenomena setiap indikator, dimana siswa cenderung tidak peduli dengan temannya yang lain bila dalam kesulitan dan kurangnya empati sesama siswa dan cenderung menyakiti baik verbal maupun non verbal. Kemudian tidak adanya rasa hormat siswa terutama kepada guru. Fasilitas yang kurang dari pihak orang tua maupun sekolah menjadikan rendahnya dukungan sosial siswa dan tidak adanya pesan dari guru maupun orang tua yang benar-benar di taati.

Dukungan sosial (sosial support) didefinisikan oleh Hupeey dan Foote (Handono, 2013) sebagai sumber daya sosial yang dapat membantu individu dalam menghadapi kejadian yang menekan. Dukungan sosial juga diartikan sebagai suatu pola interaksi yang positif atau perilaku menolong yang diberikan pada individu yang membutuhkan dukungan. Sedangkan Felton dan Berry (1992) berpendapat bahwa dukungan sosial yang sifatnya instrumental diberikan oleh orang-orang yang terdekat yang ada kaitan kekeluargaan daripada dari teman, akan mempunyai hubungan yang kuat dengan kesejahteraan psikis. Sedangkan dukungan yang sifatnya emosional akan efektif dan lebih tepat diberikan oleh orang yang bukan termasuk keluarga.

Demikian juga dengan subjective well being siswa di sekolah tersebut yang masih di dominasi oleh hasil yang rendah. Indikator kebahagiaan yang tinggi hanya dimiliki oleh 3 orang siswa saja, dan sekitar lebih dari 60\% merasa kurang bahagia.

Hal ini dapat terlihat dari fasilitas sekolah maupun perhatian pihak eksternal maupun internal yang kurang mendukung berdasarkan hasil dari dukungan sosial yang rendah menjadi mayoritas karena tingginya pengalaman yang tidak menyenangkan dan hampir setiap hari terjadi pada diri siswa di sekolah tersebut.

Seseorang dikatakan memiliki tingkat subjective well being yang tinggi apabila orang tersebut merasakan kepuasan dalam hidup seperti adanya pengalaman yang menyenangkan. 
Kepuasan hidup merupakan kepuasan terhadap kehidupan secara keseluruhan. Diener dan Biswar (Ulfah, 2014) menjelaskan komponen kepuasan hidup yaitu meliputi: kepuasan dengan masa lalu, kehidupan sekarang, kepuasan dengan pandangan masa depan, dan keinginan untuk memperbaiki hidup. Namun menurut Listian (2016) Seseorang dikatakan mempunyai tingkat subjective well-being yang tinggi jika orang tersebut merasakan kepuasan dalam hidup, sering merasakan emosi positif seperti kegembiraan dan kasih sayang serta jarang merasakan emosi negatif seperti kesedihan dan amarah.

Sementara itu menurut Myers \& Diener (Pramudhita, 2015) individu dengan Subjective well-being yang rendah, cenderung menganggap rendah hidupnya dan memandang peristiwa yang terjadi sebagai suatu hal yang tidak menyenangkan sehingga menimbulkan emosi yang tidak menyenangkan seperti kecemasan, depresi dan kemarahan.

Subjective well being akan sulit dirasakan oleh siswa karena kurangnya dukungan sosial namun pada sisi lain hal tersebut seolah wajar karena siswa dalam masa remaja. Pada tahap ini mencapai identitas diri akan sangat menonjol, pemikiran akan semakin logis, abstrak, dan idealistis.

Periode ini disebut fase pubertas (puberty) yaitu suatu periode dimana kematangan kerangka atau fisik tubuh seperti proporsi tubuh, berat dan tinggi badan mengalami perubahan serta kematanagan fungsi seksual yang terjadi secara pesat terutama pada awal masa remaja. Kebutuhan lain dari remaja adalah teman sebaya, dimana teman sebaya adalah sangat penting bagi remaja untuk mengenal dunia diluar keluarga.

Namun setidaknya ada 4 masalah remaja yang mempengaruhi sebagian bear remaja yang salah satunya juga karena masalah masalah yang berkaitan dengan sekolah (Dianada, 2018). Sekolah merupakan tempat siswa menghabiskan sebagian waktunya sehingga akan banyak masalah terkait dengan tekanan teman sebaya dan konformitas, dimana Remaja memiliki kebutuhan yang kuat untuk disukai dan diterima kawan sebaya atau kelompok. Sebagai akibatnya mereka akan senang apabila diterima dan sebaliknya.

Bagi mayoritas siswa, pandangan kawan-kawan pada dirinya merupakan hal yang paling lebih penting. Bahkan kadang lebih penting daripada orangtuanya sendiri, mereka lebih mengutamakan kawan-kawannya supaya mereka bisa diterima di komunitas teman sebaya. Karena remaja merasa sudah besar serta sudah mandiri.

Di rumah, siswa remaja belajar tentang norma-norma berperilaku yang diterapkan oleh orang tua atau seorang yang lebih tua. Tatapi remaja kadang ingin melepaskan diri dari norma-norma tersebut kalau sudah keluar dari rumah misalanya pada saat pergi ke sekolah, mereka mengikuti cara berpakaian, kebiasaan bahasa, dan peraturan teman sebaya mereka kalau tidak ingin ditertawakan atau dikucilkan apabila tidak mengikuti aturan kelompok teman sebaya mereka.

Biasanya remaja akan taat hukum disaat kelas lima Sekolah Dasar (SD), mungkin mau melanggar hukum di Sekolah Menengah Atas (SMA) jika itu diperluakan atau yang mereka pikir 
diperlukan untuk mendapatkan rasa hormat dari rekan-rekan mereka (Wade \& Tavris, 2016).

Dalam perkembangan remaja yang penuh gejolak, peranan keluarga, sekolah, masyarakat dan juga kebijakan pemerintah dalam dunia pendidikan ikut andil besar. Peranan media massa seperti televisi, internet, tabloid, koran dan majalah juga mempunyai kekuatan yang besar bagi kepentingan yang dominan dalam masyarakat.

Bagi beberapa remaja dalam pergaulan, pengalaman ditolak atau diabaikan dapat membuat mereka merasa kesepian dan menimbulkan sikap bermusuhan. Dibutuhkan kemampuan baru dalam menyesuaikan diri yang dapat dijadikan dasar dalam interaksi sosial yang lebih besar. Tekanan untuk mengikuti teman sebaya atau yang disebut konformitas (conformity) pada masa remaja sangat kuat. Konformitas muncul ketika individu meniru sikap, atau tingkah laku orang lain dikarenakan ada tekanan nyata maupun yang dibayangkan oleh mereka.

Konformitas dengan tekanan temanteman sebaya pada masa remaja dapat bersifat positif maupun negatif. Umumnya remaja terlibat dalam semua bentuk perilaku konformitas yang negatif, seperti menggunakan bahasa yang kasar, mencuri, merusak, dan mengolok-olok orangtua dan guru. Akan tetapi banyak sekali konfomitas teman sebaya yang tidak negatif dan terdiri atas keinginana untuk dilibatkan di dunia teman sebaya, seperti berpakaian seperti teman-teman dan keinginan untuk meluangkan waktu dengan anggota suatu klik.. Banyak dari remaja yang membuat kegiatan-kegiatan prososial seperti mengumpulkan uang untuk tujuan-tujuan yang bermakna (Santrock, 2002).

\section{SIMPULAN}

Berdasarkan hasil penelitian dapat ditarik kesimpulan bahwa siswa yang sekolah di Singosari Delitua belum mendapatkan dukungan sosial yang seharusnya mereka dapatkan di usia mereka. Usia remaja rentan dengan kebutuhan perhatian dan kasih sayang serta dorongan tanpa memberikan efek negatif pada mereka. Bila dukungan sosial baik akan ada suasana belajar mengajar yang baik karena merasa semua kebutuhan terpenuhi dan pada akhirnya banyak tercipta rasa yang positif pada siswa. Rasa atau efek positif ini akan memberikan siswa subjecetive well being yang tinggi.

\section{DAFTAR PUSTAKA}

Ariati J. (2010). Subjective wellbeing(kesejahteraan subjektif) dan kepuasan kerja pada staf pengajar (dosen) di lingkungan fakultas psikologi universitas diponegoro. Jurnal Psikologi Undip. 8(2). 120-121.

Darusmin D.F. (2015). Subjective well being pada hakim yang bertugas di daerah terpencil. Gadjah Mada Journal Of Psychology.1(3). Hal $192-203$.

Dianada, I. (2018). Psikologi remaja dan permasalahannya. Istighnai, 1(1). 116-133.

Felton, B.J., Berry, C. (1992). Psychology and Aging Do The Source Of Urban Elderly Social Support, Determine its Psychological Consequences. Journal Of Personality and Socail Psychology. 7:89-97

Handono, S. (2013) Upaya Menurunkan Keluhan Nyeri Sendi Lutut pada Lansia di Posyandu 
Lansia Sejahtera. Jurnal STIKES Volume 6, No. 1, Juli 2013.

Kusrini W. 2014. Hubungan dukungan sosial dan kepercayaan diridengan prestasi bahasa inggris siswakelas VIII SMP Negeri 6 Boyolali. Jurnal Penelitian Humaniora,15(2). 133- 134.

Listian S.P. \& Alhamdu. (2016). Subjective wellbeing pada pasangan yang menikah melalui proses ta'aruf. Jurnal RAP UNP. 7(1). 78-89.

Pramudita R.\& Pratisti W.D. (2015). Hubungan antara self-efficacy dengan subjective wellbeing pada siswa sma negeri 1 belitang. Seminar Psikologi \& Kemanusiaan, Psychology Forum UMM. 978-979.

Santrock J.W. (2002). Life-Span Development Perkembangan Masa Hidup. Edisi 5. Jilid 2. Jakarta: Erlangga.

Saputri S.K \& Sakti H. (2015). Dukungan sosial dan subjective well being pada tenaga kerja wanita PT. Arni family ungaran. Jurnal Empati, 4(4), 208-216.

Ulfah S.M. \& Mulyana O.P. (2014). Gambaran subjective well being pada wanita involuntary childless. character. 2(3) 3-4

Wade C. \& Tavris C. (2016). Psikologi. Ed 9. Jakarta: Erlangga. 